\title{
ENFLASYON HEDEFLEMESI VE TÜRKIYE DENEYIMI
}

\author{
Pelin ÖGE GÜNEY* \\ İbrahim Murat CEYLAN**
}

$\ddot{O} z$

$\mathrm{Bu}$ çalışma, Türkiye'deki enflasyon hedeflemesi uygulamasının performansını analiz etmektedir. Bu kapsamda enflasyon hedeflemesinin, enflasyon oynaklığı ve sürekliliği ile çıktı oynaklığı üzerindeki etkisi incelenmiştir. Para politikasının enflasyon ve büyüme üzerindeki etkisini görmek için enflasyon ve endüstriyel büyümenin para politikası şoklarına verdiği tepki, etki-tepki fonksiyonları ile tahmin edilmiş̧ir. Çalışmanın sonuçları enflasyon hedeflemesinin çıktı büyümesi üzerinde açık bir maliyet yaratmadan, enflasyonun düşürülmesi için uygun bir ortam yarattığını göstermektedir.

Anahtar Sözcïkler: Enflasyon hedeflemesi, enflasyon, etki-tepki fonksiyonları, Türkiye.

\begin{abstract}
Inflation Targetting: The Case of Turkey

This paper examines the implementation and performance of inflation targeting in Turkey. In this context, the effects of inflation targeting on inflation volatility and persistency and output volatility are discussed. The impulse responses of inflation and output growth to a monetary policy shock are also estimated to identify monetary policy impacts on these variables. Our results show that the adoption of inflation targetting is a good framework for reducing inflation without apparent costs on economic growth.
\end{abstract}

* Yrd.Doç.Dr., Hacettepe Üniversitesi, İktisat Bölümü, 06800, Beytepe-ANKARA, pelinoge@ hacettepe.edu.tr

** Türk Silahlı Kuvvetleri, ANKARA, imceylan@ gmail.com 
Keywords: Inflation targetting, inflation, impulse-response functions, Turkey.

\section{GÍRİș}

Para politikasının öncelikli amacının düşük ve istikrarlı bir enflasyon sağlamak olduğu genel olarak kabul edilmektedir. Bu amaçla döviz kuru ve parasal büyüklüklerin hedeflenmesi stratejileri, 1960'lı yıllardan itibaren birçok ülke tarafindan bir para politikası rejimi olarak kullanılmıştır. Ancak para politikasının nihai amacı olan fiyat istikrarını sağlamada, bu hedefleme stratejilerinin istenilen sonuçları vermemesi, birçok ülkeyi yeni para politikası arayışlarına itmiştir. Bunlardan biri olan enflasyon hedeflemesini Mishkin (2000) enflasyon için orta vadeli sayısal bir hedefin konulduğu, para politikasının temel hedefinin fiyat istikrarını sağlamak olduğu ve merkez bankasının şeffaflı̆̆ının ve hesap verebilirliğinin sağlanmış olduğu bir para politikası stratejisi olarak tanımlamaktadır. Bernanke ve Mishkin (1997) ise enflasyon hedeflemesini, belirli bir zaman içerisinde düşük veya durağan bir enflasyonun para politikasının uzun vadeli ve öncelikli amacı olduğunu kamuoyuna açık bir şekilde duyurulması olarak tanımlanmaktadır.

Enflasyon hedeflemesi stratejisinin enflasyonu kontrol eden diğer yöntemlerden temel farkı, para politikası araçlarının geçmiş ya da cari enflasyon yerine gelecek enflasyona dayanmasıdır. Bu rejimde merkez bankası enflasyon hedefini belirlerken ücret artışları, kur artışı, kamu fiyatlandırması, beklentiler, petrol fiyatları gibi birçok unsuru dikkate almaktadır. Tüm bu verileri kullanarak kısa ve orta vadeli enflasyon hedeflerini saptayan merkez bankası, kamuoyuna bu hedeflerin gerçekleştirileceğine dair açık taahhütlerde bulunmaktadır. Enflasyon hedefinin kolay izlenebilir olması ve enflasyonist beklentiler bakımından bir çapa görevi üstlenmesi para politikası açısından uygun bir hedef olmasını desteklemektedir. Bu strateji ile kamuoyuna para politikasının temel görevi ile ilgili net bir mesaj verilmekte ve merkez bankasının performansının değerlendirilmesi açısından bir kriter ortaya konmaktadır. Enflasyon hedeflemesinde diğer stratejilerde olduğu gibi bir ara hedef konmamaktadır. Bunun anlamı, enflasyon hedefinin para arzı gibi tek bir değişkenle enflasyon arasındaki istikrarlı bir ilişkiye dayanmamasıdır (Petursson, 2005). Tüm ekonomik veriler enflasyonist gelişmeleri etkileyebilmektedir.

Enflasyon hedeflemesi stratejisinde hesap verebilirlik, şeffaflık, kredibilite ve esneklik kavramları önem kazanmaktadır. Merkez bankasının faaliyetlerine ilişkin yayınlar yapılması, para politikası kararları ve gerekçelerinin kamuoyuna aktarılmasında önemli bir faktördür. Ayrıca merkez bankasının gelecek yıllara yönelik enflasyon hedefleri para politikasının gelecekteki olası adımları hakkında önemli bilgi sağlamaktadır. Merkez 
bankalarının hesap verebilirliklerinin artması ve şeffaf olmaları kredibilitelerini arttırmaktadır (Svensson, 1999). Esneklik, merkez bankasının kısa dönemde ortaya çıkan makroekonomik gelişmelere, enflasyon hedeflerinin elverdiği bir esneklikle tepki verebilmesini ifade etmektedir. Bernanke $v d$., (1999)'e göre enflasyon hedeflemesi, hem kurala bağlı para politikasının hem de duruma bağlı para politikasının avantajlarını barındırmaktadır. Bununla birlikte, merkez bankasına fazla esneklik tanındığında kamuoyunun güveni sarsılabilmekte, daha sık1 bir rejim uygulandığında ise reel ekonomide istikrarsızlık sözkonusu olabilmektedir. Genelde enflasyon hedeflemesi politikası, sadece enflasyonun dikkate alındığı katı enflasyon hedeflemesi ve diğer değişkenlerin de dikkate alındığı esnek enflasyon hedeflemesi olarak ayrılmaktadır (bkz. Svensson, 2001).

Enflasyon hedeflemesi politikasının sağlıklı uygulanabilmesi için bazı önkoşulların sağlanması gerekmektedir. Bunlar; merkez bankasının bağımsız olması, mali baskınlı̆̆ın olmaması, para ve sermaye piyasalarının gelişmiş olması olarak sıralanabilir. Merkez bankası ilk olarak araç bağımsızlığına sahip olmalıdır (bkz. Mishkin, Schmidt-Hebbel, 2001). Araç bağımsızlığı, merkez bankasının hedefine ulaşmak için istediği aracı yasal olarak kullanabilmesidir. Aynı zamanda merkez bankasının kamu kesimine kredi açması yasal olarak yasak olmalıdır. Kamu borç stokunun yüksek düzeyde olması, yani mali baskınlık, risk priminin ve dolayısıyla reel faizlerin yükselmesine yolaçabilmektedir. Bu durumda merkez bankası temel politika aracı olan kısa vadeli faiz oranlarını enflasyonu düşürmek için artırırsa, bu kez kamu borçlarının sürdürülebilirliği zorlaşmaktadır. Para ve sermaye piyasalarının güçlü olmaması ise, merkez bankasının öncelikle finansal istikrarı gözetmek durumunda olmasına yolaçmaktadır. Bankaların "son borçlanma merci" olan merkez bankası, bankalar para ve sermaye piyasalarından borçlanamadıklarında bankalara ihtiyaçları olan fonu sağlamak durumunda kalmakta, bu da enflasyonist sonuçları beraberinde getirebilmektedir. Enflasyon hedeflemesi rejiminin uygulanabilmesi için gerekli önkoşulların yanı sıra bazı teknik gerekliliklerin de sağlanması gerekmektedir. Bunlar, hedeflenecek fiyat endeksinin seçimi, uygun enflasyon oranının (nokta veya bant) ve hedefleme süresinin seçimidir. Hedefler tüketici fiyat endeksi üzerine konulursa, bu endeks para politikası ile ilgisi çok zayıf olan mal ve hizmet fiyatlarını içerdiğinden, bu mal ve hizmetlerin fiyatlarındaki oynamalar karşısında, para politikası gereksiz faiz tepkisi vermek durumunda kalabilmektedir. Diğer taraftan çekirdek enflasyonun seçilmesi ise para politikası ile ilişkisiz olan, ancak ekonomik birimlerin tükettiği mal ve hizmetlerin fiyatlarındaki değişmelerin dışlanması anlamına gelmektedir. Bu da enflasyon hedefinin ekonomik birimler açısından önemsiz görülmesine yolaçabilmektedir (Özatay, 2011). Bir çok ülke TÜFE üzerine hedeflerini belirlese de genel olarak çekirdek enflasyonun kullanılması önerilmektedir (Bryan vd., 1997; Roger, 1997; Folertsma, Hubrich, 2001). 
Nokta hedef seçilmesi kamuoyuna daha kesin sinyaller vermekle birlikte bu hedefin tutturulamaması merkez bankasının güvenilirliğini zedeleyebilmektedir. Hedefin bir bant olarak açıklanması ise merkez bankasına bir ölçüde esneklik sağlamakla birlikte, üst sınırın asıl hedef gibi algılanmasına neden olabilmektedir. Son olarak enflasyon hedefi bir yıllık veya çok yıllık olarak açıklanabilmektedir. Para politikalarının etkilerinin belli bir gecikme ile ortaya çıkması nedeniyle yıl sonu hedef yanında orta vadeli enflasyon hedefi açıklanmasının daha uygun olacağı ileri sürülmektedir.

Enflasyon hedeflemesi ile ortalama enflasyonun düşmesi, enflasyon oynaklığının azalması ve politika "esnek" olduğunda çıktının istikrara kavuşması beklenmektedir (Svensson, 1997). Enflasyon hedeflerinin konması, beklentileri bu düşük enflasyona bağlamakta ve makro ekonomik şokların enflasyonist etkilerinin azalmasını sağlamaktadır (Ball ve Sheridan, 2003). Nitekim, enflasyon hedeflemesinin ekonomik performansı arttırdığını öne süren çalışmalar enflasyon hedeflemesinden sonra enflasyon oranı ile oynaklığının ve faiz oranlarının azaldığını, enflasyon beklentilerinin istikrar kazandığını, üretim üzerinde istenmeyen bir etki ortaya çıkmadığını, para politikasının bağımsızlığının güçlendiğini, petrol fiyatları veya döviz kuru şoklarına verilen tepkinin azaldığını ortaya koymuşlardır. Örneğin, Mishkin ve Schmidt-Hebbel (2007) ve Svensson (2010) enflasyon hedeflemesinin büyüme, istihdam veya diğer ekonomik performans ölçütleri üzerinde olumsuz bir etki yaratmadığını göstermişlerdir. Mishkin and Posen (1997) enflasyon hedeflemesinin ekonomik performansı arttırdığına ilişkin bulgular elde etmişlerdir. Kahn ve Parrish (1998) enflasyon hedeflemesinin para politikasının kredibilitesini arttırdığını belirtmişlerdir. Levin $v d$. (2004) enflasyon hedeflemesinin enflasyon beklentilerini etkileyerek enflasyonun düşük ve istikrarlı bir düzeyde kalmasını sağladığını ileri sürmüşlerdir. Diğer taraftan, Cecchetti ve Ehrmann (1999) ve Siklos (1999) gibi bazı çalışmalar ise enflasyon hedeflemesinin ekonomik performansı arttırdığına dair bir bulgu ortaya koyamamışlar veya en azından bazı ülkelerde böyle bir etki bulunamadığını ileri sürmüşlerdir.

Enflasyon hedeflemesi uygulayan ülkelerin son yillarda artmasıyla, bu stratejinin ekonomik etkilerini inceleyen çalışmalar da artmaya başlamıştır. Bu çalışmada da 2006 yılından itibaren Türkiye'de uygulanmakta olan enflasyon hedeflemesi stratejisinin başarısı değerlendirilmektedir. Bu konuda bilindiği kadarıyla Türkiye için yapılan bir kaç çalışma mevcuttur (Ermişoğlu, 2013; Kara, Öğünç, 2008; Genç, Balcılar, 2012). Bu çalışmalar izleyen bölümde de özetlendiği gibi enflasyon hedeflemesinin enflasyon beklentilerinde veya döviz kuru değişimlerinin fiyatlar üzerindeki etkilerinde değişme yaratıp yaratmadığını incelemektedir. Bu çalışmada ise diğerlerinden farklı olarak enflasyon hedeflemesinin ekonomik büyümeyi olumsuz etkileyip etkilemediği ve para politikası şoklarının ekonomik büyüme ve enflasyon üzerindeki 
etkilerinin enflasyon hedeflemesi ile değiş̧ip değişmediği etki-tepki fonksiyonları ile analiz edilmektedir.

Çalışmanın birinci bölümünde konu ile ilgili literatür ele alınmaktadır. İkinci bölümde Türkiye'deki enflasyonist sürecin gelişimi incelenmektedir. Üçüncü bölümde temel istatistikler kapsamında Türkiye'deki enflasyon hedeflemesinin başarısı değerlendirilmektedir. Dördüncü bölümde ampirik model ve veriler ortaya konmaktadır. Sonuç bölümünde ise çalışmanın bulguları değerlendirilmektedir.

\section{LITERATÜR}

Enflasyon hedeflemesi stratejisi uygulayan ülkelerin ekonomik performansını ampirik düzeyde araştıran çalışmalar, bu stratejinin uygulama döneminde, enflasyon oran1 ve oynaklığı, faiz oran1, çıktı büyümesi ve oynaklığı gibi göstergelerdeki değişiklikleri incelemektedir. Bazı çalışmalar enflasyon hedeflemesi uygulayan ve uygulamayan ülkelerin performanslarını karşılaştırırken, bazı çalışmalar ülkeleri enflasyon hedeflemesi öncesi ve sonrası dönemde yine bu göstergeler açısından ele almaktadır.

Enflasyon hedeflemesi uygulayan ve uygulamayan ülke performanslarını karşılaştıran çalışmalardan bazıları enflasyon hedeflemesi lehine sonuçlar elde etmişlerdir. Örneğin, Corbo $v d$., (2002) enflasyon hedeflemesi uygulayan ülkelerde üretimdeki dalgalanmaların ve enflasyon sürekliliğinin azaldığını, ayrıca enflasyon tahmin hatalarının ve enflasyon şoklarının çıktı üzerindeki etkisinin de düştügünü göstermişlerdir. Neumann ve von Hagen (2002) enflasyon hedeflemesinin enflasyonun düşürülmesi ve oynaklığının azaltılması açısından başarılı olduğunu göstermişlerdir. Petursson (2004), enflasyon hedeflemesinin ekonomi üzerindeki etkilerini 21 ülkede incelemiş ve bu stratejiyi uygulayan ülkelerin enflasyonu düşük seviyelerde tutma konusunda iyi bir performans sergilediğini göstermiştir. Ayrıca bu ülkelerde enflasyon ataletinin kırıldığ 1 ve enflasyon oranlarındaki dalgalanmalarda düşüş eğiliminin ortaya çıtığı ifade edilmiştir. Mishkin and Schmidt-Hebbel (2007), enflasyon hedeflemesinin daha düşük enflasyona ulaşmaya yardımcı olduğunu, enflasyonun petrol fiyatları ve döviz kuru şoklarına daha az cevap verdiğini ve para politikasının etkinliğini arttırdığını göstermişlerdir. Neyaptı (2012) 166 ülkeyi inceleyerek enflasyon hedeflemesi uygulayan ülkelerin, uygulamayanlara göre 2000'li yıllarda ortalama olarak daha düşük enflasyona sahip olduklarını göstermiştir. Bazı çalışmalarda ise genel olarak enflasyon hedeflemesi lehine sonuçlara ulaş1sa da bu stratejinin kimi yetersizlikleri ortaya konmuştur. Örneğin, Levin $v d$., (2004), enflasyon hedeflemesinin endüstrileşmiş ülkelerde enflasyon beklentilerini etkilemekte ve enflasyon sürekliliğini azaltmakta önemli bir rol oynadığını göstermişlerdir. Ancak gelişmekte olan ülkelerde 
enflasyon hedeflemesinin enflasyon beklentilerinin hemen uyarlanmasina yolaçmadığı ve enflasyon oynaklığının yüksek olmaya devam ettiği görülmüştür. Johnson (2002) ise, enflasyon hedeflemesi uygulayan beş ülke (Avustralya, Kanada, Yeni Zelanda, İsveç ve İngiltere) ile uygulamayan altı ülkede (Fransa, Almanya, İtalya, Hollanda Japonya ve ABD) enflasyon hedeflemesinin beklenen enflasyon üzerindeki etkilerini incelemiştir. Beklenen enflasyon seviyesinde enflasyon hedeflemesinin ilanından sonra düşüş olduğu görülmüştür. Öte yandan fiili enflasyon oranlarının enflasyon hedeflemesini uygulayan ve uygulamayan bütün ülkelerde düştüğü saptanmıştır.

Enflasyon hedeflemesinin ekonomik performansı arttırdığına ilişkin bulgular ortaya koymayan çalışmalar da mevcuttur. Cecchetti ve Ehrmann (1999) enflasyon hedeflemesi stratejisinde enflasyon oynaklığı ile çıtı oynaklığı arasındaki ilişkiyi incelemişlerdir. Enflasyon hedeflemesine geçişin bir anlamda para politikası yapımcılarının tercihlerinin değişerek, çıktı oynaklığına göre enflasyon oynaklığının azaltılmasına daha fazla önem vermeleri anlamına geldiğini belirtmişlerdir. Ancak analizlerinde hem enflasyon hedeflemesi uygulayan hem de uygulamayan ülkelerde enflasyon oynaklığının azaltılması yönünde politikalar izlendiği ortaya konmuştur. Dolayısıyla enflasyondaki düşmenin enflasyon hedeflemesinden kaynaklanmadığını, bunun genel bir eğilim olduğunu ileri sürmüşlerdir. Ball ve Sheridan (2003), enflasyon hedeflemesi uygulayan yedi ülke ile uygulamayan on üç OECD ülkesinin makroekonomik performansını karşılaştırmıştır. Çalışmada, enflasyon hedeflemesine geçilen yıllardan sonra hem bu stratejiyi uygulayan hem de uygulamayan ülkelerde ekonomik performansın birçok yönden iyileştĭgi belirtilmiştir. Sonuç olarak, enflasyon hedeflemesinin ülkelerin ekonomik performansını iyileştirdiğine ilişkin bir kanıt elde edilememiş, ancak enflasyon hedeflemesinin gelecekte ekonomik performansı iyileştirebileceği vurgulanmıştır. Lin ve Ye (2009) ise enflasyon hedeflemesi uygulayan yedi ülkede bu stratejinin enflasyon ve enflasyon oynaklığı üzerinde belirgin bir etki yaratmadığını ortaya koymuştur.

Enflasyon hedeflemesinin performansinı sadece bu stratejiyi uygulayan ülkeleri ele alarak analiz eden çalışmalar da mevcuttur. Mendonça (2007), örtük enflasyon hedeflemesi uygulayan on dört ülkede enflasyon hedeflemesi ile enflasyon oranı, faiz oranı ve ekonomik büyüme değişkenleri arasındaki ilişkiyi incelemiştir. Enflasyon hedeflemesinin enflasyon oranını düşürdüğü, ayrıca ekonomik büyüme üzerinde belirgin maliyetler oluşturmadan faiz oranlarının azalmasına katkı sağladığ 1 görülmüştür. Ancak kısa dönemde işsizlik oranlarının arttığı ortaya konmuştur. Bernanke vd., (1999) enflasyon hedeflemesi uygulayan dokuz ülkede enflasyonun düş̧üğünü, enflasyon beklentilerinin ve nominal faiz oranlarının azaldığını, fiyat düzeyindeki bir defalık şokların enflasyona etkisinin yine azaldığını gözlemlemişlerdir. Tüm bu 
gelişmelerin ekonomik büyüme için uygun bir ortam yarattığını belirtmişlerdir. Tagushi, Kato (2010) da enflasyon hedeflemesi uygulayan dört gelişmekte olan ülkeyi (Kore, Endonezya, Tayland, Filipinler) ele almışlar ve Filipinler dışında diğer ülkelerde uygulanan enflasyon hedeflemesi politikasının, enflasyonist beklentilerin düşmesine yol açarak, enflasyonu frenlemek için iyi bir çapa olarak kullanıldığını görmüşlerdir. Kim, Park (2006), Kore'de uygulanan enflasyon hedeflemesinin fiyat istikrarını sürdürmede etkili bir rol oynadığını göstermiştir. Enflasyon hedeflemesine geçişten itibaren, enflasyon oranlarında ve oynaklığında düşüş olmuş, enflasyon beklentileri enflasyon şoklarına daha az duyarlı hale gelmiştir.

Türkiye'de enflasyon hedeflemesi üzerine yapılan çalışmara bakarsak, Ermişoğlu (2013) enflasyon hedeflemesinin enflasyon beklentilerinin oynaklığını azalttığını ve enflasyon beklentileri oluşturulurken enflasyon hedeflerinin baz alındığını göstermiş, dolayısıyla enflasyon hedeflemesinin enflasyon üzerinde olumlu etkisi olduğu sonucuna varmıştır. Kara ve Öğünç (2008), enflasyon hedeflemesinden sonra döviz kurundaki değişmelerin fiyatlara yansımasını (pass through) incelemişler ve enflasyon hedeflemesi politikası uygulanmasıyla birlikte döviz kurundaki değişmelerin fiyatlara yansımasının azaldığını ortaya koymuşlardır. Genç ve Balcılar (2012) ise Türkiye'de enflasyon hedeflemesinin enflasyonu düşürmekteki etkinliğine bakmışlar ve enflasyondaki düşmenin enflasyon hedeflemesi rejiminin uygulmasına atfedilemeyeceğini ileri sürmüşlerdir.

\section{TÜRKIYE'DEKİ ENFLASYONIST SÜREÇ}

Türkiye 1970'lerin ortalarından 2000'li yılların başına kadar sürekli ve yüksek seviyede enflasyon değerleriyle karşı karşıya kalmıştır. Bu süreç boyunca enflasyonu düşürme amacıyla pek çok program uygulanmış, ancak kalıcı bir başarı sağlanamamıştır. Enflasyon oranı en yüksek seviyesine \%107.3 ile ekonomik kriz y1lı olan 1994 senesinde çıkmış, en düşük düzeyi olan \%6.2 seviyesine ise, enflasyon hedeflemesi rejiminin uygulanmakta olduğu 2012 yılında inmiştir. Söz konusu dönemde en yüksek büyüme oranı \%9.9 ile 2004 y1lında, en düşük büyüme oranı $-\% 9.5$ ile yine kriz yılı olan 2001 y1lında gerçekleşmiştir.

24 Ocak 1980 tarihinde ilan edilen ekonomik istikrar programı ile ithalatın serbestleştirilmesi, esnek döviz kuru rejiminin benimsenmesi, ihracat ve yabancı sermayenin teşvik edilmesi, fiyat kontrollerinin kaldırılması ve sıkı maliye politikası uygulanmasını öngörülmüş ve ekonomik serbestleşmenin ilk

adımı atılmıştır. Bu programla 1981 y1lında enflasyon \%101.4 seviyesinden \%34 seviyesine gerilemiş ve 1982 yılında da yaklaşık \%25 seviyesine 
düşürülerek önemli bir başarı sağlanmıştır. Ancak, IMF ile yapılan stand-by anlaşmasının 1986 yılında sona ermesi, sıkı maliye politikalarından vazgeçilmesi ve özellikle kamu yatırımlarının artırılması, enflasyon üzerinde olumsuz etkilere neden olmuştur. 1987 y1lında \%33.5 düzeyinde olan enflasyon 1988 yılında \%69.7'e çıkmıştır. Bu nedenle 1988 yılında yüksek döviz kuru politikasından vazgeçilmiş ve enflasyonun kontrol altında tutulması için Türk Lirasının reel olarak değer kazanması sağlanmıştır (Aşıkoğlu, Uçtum, 1992).

1980'li yılların başlarında bütçe açıkları genellikle Merkez Bankası kaynakları kullanılarak finanse edilmiştir. Ancak 1980'li yılların sonlarına doğru yapılan reformlarla Hazine'nin Merkez Bankası'ndan alacağı kısa vadeli avanslara sınırlama getirilmiş ve bütçe açıklarının finansmanında yurtiçi borçlanma giderek ağırlık kazanmaya başlamıştır. Yurtiçi borçlanmanın önemli bir özelliği çok kısa vadeli olmasıdır. Yüksek faizle kısa vadeli borçlanma, borçların geri ödenmesi için borçlanma gereksinimini de artırmış ve sonuçta yüksek bütçe açıkları - yüksek faiz oranları sarmalına neden olmuştur. 1993 yılından itibaren kamu açıklarını kapatmak için hem merkez bankası kaynaklarına daha fazla başvurulmuş, hem de dış borç kullanımı artmıştır. Aynı zamanda faiz hadleri idari kararlarla düşürülmeye çalışılmış, tahvil ve bonolara vergi uygulaması başlatılmıştır. Bu politikaların sonucunda kamu kağıtlarına olan talep düşmüş, sistemdeki likidite fazlası dövize yönelmiştir. İç borç vadesinin kısalması, reel faizlerin yükselmesi ve sürekli yükselen kamu açıkları, ekonomik birimleri devletin borçlarını ödeyebileceği konusunda şüpheye sokmuştur. Merkez Bankası döviz kurunu sabitlemek için rezervlerinin büyük bir kısmını kullanmak zorunda kalmıştır. Ekonominin temel dengeleri bozuk olduğu için yapılan müdaheleler başarılı olamamış ve köklü değişiklikler yapılmasını gerekli kılmıştır.

5 Nisan 1994 tarihinde uygulamaya konan istikrar tedbirleri ile enflasyon hedefine ulaşmak amacıyla sıkı para ve kredi politikaları hazırlanmıştır. Bu programda ayrıca döviz kurları, uluslararası rezervler ve net iç varlıklar hedeflenmiştir. Döviz rezervlerindeki hızlı azalış ve faizlerdeki artış karşısında, Merkez Bankası rezervlerini artırmak ve para piyasalarında istikrarı sağlamak için yoğun çaba harcamıştır. Bu programla Türk Lirası devalüe edilmiş, çeşitli vergi düzenlemelerine gidilmiş ve kamu harcamalarında kısıtlamaya gidilmiştir. 5 Nisan kararları, döviz ve sermaye piyasalarının istikrara kavuşturulmasında, kamu kesimi borçlanma gereksiniminin (KKBG) düşürülmesinde başarılı olmuştur. KKBG/GSMH oranı 1993 yılındaki \%10.2 düzeyinden 1994 y1lında \%6.16 düzeyine, 1995 y1lında ise \%4.97 düzeyine kadar inmiştir. Fakat tahvil piyasasının işlerliğini sağlamak için yüksek faiz oranlarından borçlanmaya devam edilmesi (1994 yılı bileşik borçlanma faiz oranı ortalama olarak \%164.4 oranında gerçekleşmiştir) iç borç stokunu da artırmıştır. Krizin atlatılmasına karşın kamu açıkları sorunu giderilemediği için mali istikrar da 
sağlanamamıştır. Siyasi istikrarsızlık ve sık-sık yapılan seçimler mali genişlemeye neden olmuş, iç borç stoku hızla artmaya devam etmiş̧ir. 19961997 yıllarında para politikası temelde mali piyasalara istikrar sağlamayı amaçlamıştır.

1998 yılının Temmuz ayında IMF ile Yakın İzleme Anlaşması imzalanmıştır. Vergi yasasında yeni düzenlemeler yapılmıştır. Bu düzenlemeler kamu gelirlerinde bir düşüşe yol açarken; 1999 yılı Mart ayında erken seçim kararının alınması ve 1999 yılının ikinci yarısında yaşanan doğal felaket sonucu ortaya çıkan maliyetler nedeniyle kamu harcamalarında planlanan kısıntı gerçekleştirilememiştir. Sonuç olarak, mali istikrarsızlık daha da derinleşmiş ve kriz öncesi yıl olan 1993 yılının sonuçlarından da daha kötü sonuçlar ortaya çıkmıştır. 17 Ağustos depreminin yol açtığı maliyetleri karşılamak için 1999 yılı sonlarında yeni bir vergi paketi uygulamaya konarak ek vergiler yürürlüğe girmiştir.

Türkiye 9 Aralık 1999 tarihinde kur çapasına dayanan bir istikrar programı uygulamaya başlamış, 1 ABD Doları ve 0.77 Alman markından oluşan döviz sepetinin fiyatının, önceden açıklanan oranlarla devalüe edileceği belirtilmiştir. Önceden açıklanan kurun enflasyonla mücadelede en önemli sorunlardan biri olan geçmiş enflasyona endeksleme alışkanlığının önlenmesine destek vereceği öngörülmüştür. Program kapsamında merkez bankası bilançosu temel kalemlerinde "Net İç Varlıklar" büyüklüğüne tavan getirilmiş, ayrıca "Net Uluslararası rezervler" kaleminin minimum düzeyi belirlenmiştir. Diğer taraftan, sosyal güvenlik, tarım gibi pek çok alanda kapsamlı reformlar yapılması, önemli KİT'lerin özelleştirilmesi öngörülmüsşür. Fakat reformların yapılamaması ve kamu harcamalarının istenen oranda kisılamaması nedeniyle bütçe açıkları beklenen oranda düşmemiştir. 1999 yılında deprem ve ekonomik daralma nedeni ile \%11.9'a çıkan bütçe açıklarının GSMH'ya oranı 2000 yılında ancak \%10.9'a gerilemiştir. İç borç stokunun GSMH'ya oranı ise \%29.3'ten sadece \%29'a gerilemiştir. Kamu kesiminin mali durumundaki kısmi iyileşme kısıtlı olunca, enflasyon oranındaki düşüş de beklendiği kadar olmamıştır. Enflasyon oranı programda açıklandığı gibi düşmediği için (TÜFE'nin \%25 olması öngörülürken, gerçekleşme \%39 olduğundan) Türk Lirası hızla değer kazanmış ve dış ticaret açığı artmıştır. 2000 yılının Kasım ayında ortaya çıkan sorunlar programın sürdürülebilirliliği konusunda kuşkuları artırmıştır. Alınan geçici önlemler yeni bir krizin çıkmasını önleyemese de bir süreliğine erteleyebilmiştir. Ancak Türk Lirasına yapılan spekülatif saldırıların önünün kesilemeyeceği anlaşılınca kur 2001 yılı Şubat ayında serbest dalgalanmaya bırakılmış ve istikrar politikalarında köklü değişikliğe gidilmiştir.

2002 yılından itibaren enflasyonla mücadele amacıyla örtük enflasyon hedeflemesine geçilmesi, daha sonra ise açı enflasyon hedeflemesi 
uygulanması öngörülmüştür. ${ }^{1}$ 2002-2005 yılları arasında para politikası stratejisi olarak örtük enflasyon hedeflemesi stratejisinin uygulanma nedeni enflasyon hedeflemesi uygulanması için gerekli koşulların henüz oluşmamış olmasıdır. Bunlar, mali baskınlık, geçmiş enflasyona bağlı fiyatlama alışkanlıklanı, gelecekteki enflasyonun önemli ölçüde döviz kurundaki değişmelere bağlı olması ve finansal sistemin merkez bankası politika sinyallerine gerektiği şekilde tepki veremeyecek durumda olması olarak siralanabilir (Ersel, Özatay, 2008).

Enflasyon hedeflemesi rejiminin ön koşullarını sağlama bağlamında TCMB kanununda 25 Nisan 2001 tarihinde yapılan değişiklikle, TCMB'nin temel amacının fiyat istikrarını sağlamak olduğu belirtilmiş ve bu amacın gerçekleştirilmesi için gerekli araçların seçimi Merkez Bankasına bırakılmıştır. Yine TCMB'da yapılan değişiklikle merkez bankasının kamu kurumlarına avans vermesi ve kredi açması yasaklanmıştır. Kamu bankalarının yeniden yapılandırılması, bankaların sermaye yeterlilik oranlarının artırılması, bağımsız düzenleme ve denetleme kurullarının oluşturulması, bütçe disiplinin sağlanması gibi önlemlerle de mali baskınlığın azaltılması desteklenmeye çalışılmıştır. Enflasyon hedeflemesi rejiminin özelliklerinden bir diğeri olan şeffaflık bağlamında ise Para Politikası Kurulu'nun belli dönemlerle raporlar hazırlayarak kamuoyunu para politikasının hedefleri ve uygulamaları ile ilgili olarak bilgilendirmesi karara bağlanmıştır.

Örtük enflasyon hedeflemesi süresince enflasyon hedefleri tutturulmuş ve 2005 sonunda enflasyon oranı \%7,7 olarak gerçekleşerek enflasyon hedeflemesine geçiş için makul bir düzeye inmiştir. Diğer taraftan söz konusu dönemde ekonomik büyüme oranı ortalama \% 7 civarında gerçekleşmiştir. Örtük enflasyon hedeflemesi programıyla enflasyonla mücadele konusunda elde edilen başarının ardından, Merkez Bankası tarafından Aralık 2005 yılında yapılan bir duyuru ile 2006 yılı başından itibaren açık enflasyon hedeflemesi rejimine geçileceği bildirilmiştir. Ancak bu dönemde dünyada yaşanan ekonomik gelişmeler Türkiye ekonomisini de olumsuz yönde etkilemiştir. 2006 yılı Mayıs ayından itibaren uluslararası sermaye koşullarının gelişmekte olan ülkeler aleyhine değişmesi pek çok ülke gibi Türkiye'den de sermaye çıkışlarına neden olmuştur.

2006 yılından itibaren uygulanan açık enflasyon hedeflemesi dönemi incelendiğinde, Tablo 1'den görüldüğü gibi, 2009 ve 2010 y1lları hariç, hedeflerin tutmadığı görülmektedir. Bunda 2005 yılından sonra uluslararası piyasalarda yaşanan dalgalanmaların ve enerji fiyatlarındaki yükselmenin etkisi olmuştur. 2008 y1lında küresel ekonomik krizin etkisiyle ekonomik daralma baş göstermiş ve bunun da etkisiyle enerji ve emtia maliyetlerindeki yüksek oranlı artışlar ve uygulanan ek vergiler enflasyon üzerinde baskı yaratmıştır. 2009 
y1lında devam eden küresel krizin etkileriyle talepte meydana gelen daralma ve kriz başlangıcına göre enerji fiyatlarındaki gevşeme nedeniyle enflasyon, belirlenen hedefin altında bir oran olan \% 6,53 olarak gerçekleşmiştir (TCMB, 2009). 2010 yllında krizin etkileri hafiflemeye başlamış ve üretim kriz öncesi seviyesinin üzerine çıkmıştır (TCMB, 2010). Bu nedenle enflasyon oranları yılın ilk aylarında yükselerek \%10 seviyelerinin üzerine çıkmış, Merkez Bankası'nın piyasadaki likiditeyi azaltması ve zorunlu karşılık oranlarını artırması ile yılsonu enflasyon oranı \%6.4'e gerilemiştir. 2010 yılı sonundan itibaren TCMB fiyat istikrarı yanında finansal istikrarı da desteklemiştir. Tek bir araç ile birden fazla değişken kontrol edilemeyeceğinden TCMB, politika faiz yanında, zorunlu karşlıklar ve faiz koridoru gibi tamamlayıcı nitelikte araçlar kullanmaya başlamıştır. Kısa vadeli sermaye girişini ve kredi genişlemesini yavaşlatmak için kısa vadeli faizler düşük tutulurken, zorunlu karşıllık oranları arttırılmış, faiz koridoru genişletilmiştir. 2011 yılında ise enflasyon \% 10,45 seviyesine ulaşarak hedeflenen \%5.5 değerinin oldukça üzerine çıkmıştır. Tahminlerdeki sapmada işlenmemiş gıda fiyatlarında öngörülenin üzerinde gerçekleşen artışlar ve Türk lirasında gözlenen değer kaybının sürmesi etkili olmuştur (TCMB , 2012). 2011 yılı son çeyreğinde TL zorunlu karşl1ıkların belirli bölümünün isteğe bağlı olarak döviz ve altınla ödenebilmesi yaklaşımını benimsemiştir (Rezerv opsiyon mekanizması). TCMB, 2013 yılı son çeyreğinden başlayarak kaldıraca dayalı zorunlu karşılık oranları uygulayacağını açıklamıştır. $\mathrm{Bu}$ yolla bankaların sermaye yapılarını güçlendirmek amaçlanmaktadır.

\section{TEMEL İSTATISTIKLER}

\subsection{Gerçekleșen ve Hedeflenen Enflasyon Değerleri}

Türkiye'de enflasyon hedeflemesi rejimini değerlendirmek için öncelikle hedeflenen enflasyon ile gerçekleşen enflasyon oranları karşılaştırılmaktadır. Tablo 1'de enflasyon hedeflemesine geçiş sürecinden itibaren para otoritesi tarafindan hedeflenen yıllık enflasyon oranları ve gerçekleşen enflasyon oranları görülmektedir.

Tablo 1. Hedeflenen ve Gerçekleşen Enflasyon Değerleri

\begin{tabular}{|l|c|c|c|c|c|c|c|c|c|c|c|c|}
\hline & $\mathbf{2 0 0 2}$ & $\mathbf{2 0 0 3}$ & $\mathbf{2 0 0 4}$ & $\mathbf{2 0 0 5}$ & $\mathbf{2 0 0 6}$ & $\mathbf{2 0 0 7}$ & $\mathbf{2 0 0 8}$ & $\mathbf{2 0 0 9}$ & $\mathbf{2 0 1 0}$ & $\mathbf{2 0 1 1}$ & $\mathbf{2 0 1 2}$ & $\mathbf{2 0 1 3}$ \\
\hline Hedef & 35 & 20 & 12 & 8 & 5 & 4 & 4 & 7,5 & 6,5 & 5,5 & 5 & 5 \\
\hline Gerçekleşme & 29,7 & 18,4 & 9,3 & 7,7 & 9,7 & 8,4 & 10,1 & 6,5 & 6,4 & 10,4 & 6,2 & 7,4 \\
\hline
\end{tabular}

Kaynak: TCMB verileri 
Tablodan örtük enflasyon hedeflemesi süresince (2002-2005) enflasyonda düşüş trendinin devam ettiği ve gerçekleşen enflasyonun hedeflenen enflasyon oranlarının altında gerçekleştiği görülmektedir. Açık enflasyon hedeflemesine geçilen 2006 y1lından itibaren ise enflasyonun dalgalı seyrettiği ve 2009 ve 2010 yılı dışında enflasyonun hedeflenen düzeyin üzerinde olduğu görülmektedir. Özellikle 2006-2008 yılları arasındaki ve 2011 yılındaki dalgalı enflasyon oranlarının nedeni olarak, dönem dönem yaşanan küresel krizler gösterilebilir.

\subsection{Ortalama Enflasyon ve Enflasyon Oynaklığı}

Enflasyon hedeflemesi ilk olarak enflasyon hedeflerine ulaşıllp ulaşılmadığı ile değerlendirilse de bu oldukça katı bir yaklaşım olmaktadır. Zaman zaman merkez bankaları ekonomik koşullar gereği hedeflerinden geçici sapmalar gösterebilmektedir. Petturson (2004) enflasyon hedeflemesinin orta vadede para politikası için kredibil bir çıpa sağlaması gerektiğini belirtmekte, bu nedenle enflasyon hedeflemesinin başarısının, merkez bankalarının enflasyonu istikrarlı bir fiyat düzeyine getirerek bu düzeyde tutabilmeleri ile değerlendirilmesinin daha uygun olduğunu ileri sürmektedir. Schaechter $v d$. (2000) hedeflerden geçici sapmaların merkez bankalarının kredibilitesini çok fazla etkilemediğini belirtmektedir.

Tablo 2'de enflasyon hedeflemesi öncesi dönem (1990:1-2001:12), örtük enflasyon hedeflemesi dönemi (2002:1-2005:12) ve açik enflasyon hedeflemesi dönemi (2006:1-2013:08) için ortalama enflasyon oranları görülmektedir. Buna göre hem örtük enflasyon hedeflemesi döneminde hem de açık hedeflemesi döneminde enflasyon ciddi oranda düşüş sergilemektedir. Örtük enflasyon hedeflemesi öncesi dönemde \%4.7 olan ortalama enflasyonun, örtük enflasyon hedeflemesi döneminde \%1.3'e, açık enflasyon hedeflemesi dönemi ise \% 0.6 'ya düştüğü görülmektedir.

Jonas ve Mishkin (2003) enflasyon hedeflemesinin enflasyondaki dalgalanmaların azalamasına katkı sağladığını belirtmektedir. Dolayısıyla enflasyon hedeflemesi rejimini değerlendirirken enflasyon oynaklığının enflasyon hedeflemesi sonrasında azalıp azalmadığına bakılabilir. Enflasyon oynaklığı ile enflasyon arasında pozitif yönlü ilişki olması (bkz. Friedman, 1997; Cukierman, Meltzer, 1986; Ball, 1992), ayrıca yüksek enflasyon oynaklığının beklentileri olumsuz yönde etkilemesi ve uygulanan politikaların kredibilitesini azaltması nedeniyle enflasyon oynaklığının azaltılması arzu edilmektedir (Akyazı, Ekinci, 2008). Tabloda yine üç dönem için enflasyon oynaklığının bir ölçümü olan standart sapma değerleri görülmektedir. 
Tablo 2. Ortalama Enflasyon ve Enflasyon Oynaklığı

\begin{tabular}{ccc}
\hline & Ortalama Enflasyon & Enflasyon Oynaklı̆̆ 1 \\
\hline 1990:1-2001:12 Dönemi & 4.7 & 2.6 \\
2002:1-2005:12 Dönemi & 1.3 & 1.1 \\
2006:1-2013:08 Dönemi & 0.6 & 0.8 \\
\hline
\end{tabular}

Örtük enflasyon hedeflemesi öncesi dönemde 2.6 olan enflasyon oynaklığ 2002:1-2005:12 ve 2006:1-2013:08 dönemlerinde sirası ile 1.1 ve 0.8 değerlerini almıştır. Enflasyon hedeflemesinin enflasyondaki dalgalanmaları azalttığı görülmektedir. Dolayısıyla, enflasyon hedeflemesi enflasyonun istikrar kazanmasına katkı sağlamış görünmektedir.

\subsection{Enflasyon Sürekliliği}

Enflasyon hedeflemesi rejiminin başarısının bir göstergesi enflasyon sürekliliğinin azalması, yani enflasyon şoklarının giderek daha hızla kaybolmasıdır (King, 2002). Para otoritelerinin hedefledikleri enflasyona ulaşmak için enflasyon şoklarını giderici politikalar uygulamakta daha istekli olmaları ve para politikasının kredibilitesinin artması enflasyonun sürekliliğinin azalmasını sağlayacaktır. Ayrıca ilan edilen enflasyon hedefleri, enflasyon beklentilerinin ileriye dönük olarak (forward looking) oluşturulmasını sağlamaktadır. Enflasyon hedeflemesinin enflasyon sürekliliğine etkisini görmek için üç ayrı dönemde gerçekleşen aylık enflasyon oranlarına göre otokorelasyon hesaplamaları tabloda verilmiştir.

Tablo 3. Enflasyon Sürekliliği

\begin{tabular}{lcccc}
\hline & $\mathbf{1}$ & $\mathbf{3}$ & $\mathbf{5}$ & $\mathbf{1 2}$ \\
\hline 1990:1-2001:12 Dönemi & 0.34 & -0.17 & 0.10 & 0.26 \\
2002:1-2005:12 Dönemi & 0.58 & 0.11 & 0.08 & 0.27 \\
2006:1-2013:08 Dönemi & 0.20 & -0.19 & 0.04 & 0.33 \\
\hline
\end{tabular}

Tablo 3'den görüldüğü gibi otokorelasyon değerleri özellikle açı enflasyon hedeflemesi döneminde enflasyon sürekliliğinin azaldığını ortaya koymaktadir.

\subsection{Ortalama Büyüme ve Çıktı Oynaklığı}


Enflasyon hedeflemesinin ortalama çıtı büyümesini etkilemesi için açık bir teorik neden olmadığ 1 belirtilmekle birlikte (bkz. Ball, Sheridan, 2003), enflasyon hedeflemesinin ekonomik büyüme üzerinde geçici de olsa olumsuz etkisinin olabileceği literatürde tartışılmaktadır (örn, Firedman, Kuttner, 1996). Diğer taraftan, enflasyon hedeflemesi ile düşük enflasyon seviyesine ulaşılmasının reel ekonomi için olumlu bir ortam yaratacağı ve reel ekonomik büyümeyi destekleyeceği de ileri sürülmektedir (bkz. Mishkin, 1999). Çıktıdaki oynaklık konusunda ise "esnek" enflasyon hedeflemesinin enflasyonla birlikte çıktıya da istikrar kazandırdığı bazı ekonomistler tarafından kabul edilse de örneğin Cecchetti ve Ehrmann (1999), enflasyon hedeflemesinin çıktıyı daha oynak yaptığını ileri sürmektedir. Buna göre, para otoritelerinin enflasyonu etkileyen şokların etkilerini ortadan kaldırmak için çıktı açığını kullanmaları, çıktı oynaklığının artmasına yolaçabilecektir. Para otoritelerinin enflasyon oynaklığ1 ve çıktı oynaklığı arasında bir tercih yapmaları gerektiği kabul edilirse, enflasyon hedeflemesine geçiş, enflasyondaki oynaklığın azalması ve çıktıdaki oynaklığın artması ile sonuçlanacaktır.

\section{Tablo 4. Ortalama Büyüme ve Çıktı Oynaklığı}

\begin{tabular}{lcc}
\hline & Ortalama Büyüme & Çıktı Oynaklığ \\
\hline 1990: 1-2001: 12 Dönemi & 0.5 & 8.3 \\
2002: 1-2005: 12 Dönemi & 1.3 & 8.8 \\
2006: 1-2013: 08 Dönemi & 0.3 & 8.2 \\
\hline
\end{tabular}

Tablo 4'de üç dönem için ortalama büyüme oranları ve çıktı büyümesinin standart sapmaları verilmektedir. Veriler incelendiğinde, örtük enflasyon hedeflemesi döneminde ortalama büyümenin arttığı, açı enflasyon hedeflemesi döneminde ise azaldığı görülmektedir. Çıktıdaki oynaklık ise enflasyon hedeflemesi döneminde, enflasyon hedeflemesi öncesi döneme oranla küçük bir miktar azalma göstermektedir. Enflasyon hedeflemesi döneminde ortalama büyümenin azaldığı, diğer taraftan çıktının biraz daha istikrarlı olduğu söylenebilir.

Dolayısıyla, enflasyon sürekliliğindeki azalmanın, daha yüksek çıktı oynaklığı pahasına gerçekleşmediği söylenebilir. Bu, enflasyon hedeflemesinin politika yapımcıların karşıkarşıya oldukları enflasyon-çıktı açığı ikilemini arttırdığını göstermektedir.

\section{AMPIRİK MODEL}


Para politikasının enflasyon ve üretim üzerindeki etkisinin enflasyon hedeflemesi rejimi ile değişip değişmediği 1990:01-2012:06 dönemini kapsayan aylık veriler kullanılarak, aşağıda tanımlanan VAR (Vektör Otoregresif) modeli çerçevesinde tahmin edilmiştir:

$$
\begin{aligned}
& A(L) X_{t}=u_{t} \\
& A(L)=I-A_{1} L-A_{2} L^{2}-\cdots-A_{P} L^{p} \\
& \mathrm{E}\left(u_{t}\right)=0, \quad \mathrm{E}\left(u_{t}, u_{t}\right)=\sigma^{2}, \quad t \neq s \text { için } \mathrm{E}\left(u_{t}, u_{s}\right)=0 \text { ve } \mathrm{E}\left(X_{t}, u_{s}\right)=0 \\
& X_{t}=\left(I P_{t}, C P I_{t}, I R_{t}\right)
\end{aligned}
$$

Burada $X_{t}(1 \mathrm{xn})$ mertebesinde zaman serileri vektörü, A (nxn) tertibinde katsayılar matrisi, $\mathrm{u}(\mathrm{nx} 1)$ tertibinde hata terimleri, $\mathrm{L}$ ise gecikme operatörüdür (yani, $L^{j} X_{t}=X_{t-j}$ ). $X_{t}$ vektöründeki değişkenler IPt; endüstriyel üretim büyümesi, CPIt; tüketici fiyat endeksi ve IRt; bankalararası gecelik basit faiz oranidır. $^{2}$

Çalışmada kullanılan endüstriyel üretim ve tüketici fiyat endeksi verileri International Financial Statistic (IFS) veri tabanından, bankalararası gecelik basit faiz oranları ise Türkiye Cumhuriyeti Merkez Bankası (TCMB) EVDS sisteminden elde edilmiştir. VAR analizinde gecikme uzunluğu Akaike Bilgi Kriteri (AIC)'ne göre belirlenmiştir. Dışsal bir para politikası şokuna enflasyon ve üretim değişkenlerinin verdiği tepkiyi görmek ve bu tepkinin örtük enflasyon ve açık enflasyon hedeflemesi dönemlerinde değişip değişmediğini görmek için etki-tepki fonksiyonları tahmin edilmiştir.

Etki-tepki fonksiyonu grafiklerinde dikey eksende, ilgili değişkene verilen bir standart sapmalık artış şokuna diğer değişkenlerin verdiği tepkinin yönü ve yüzde olarak büyüklüğü, yatay eksende ise ay ölçeğinde şokun verilmesinden sonra geçen aylık süre gösterilmektedir. Kesikli çizgiler, iki standart hata bandıdır ve dolayısıyla, istatiksel anlamlılığın bir ölçütü olarak kullanılabilir. Bilindiği gibi, VAR modelinden elde edilen etki tepki fonksiyonları değişkenlerin sıralamasına duyarlıdır. Ön sırada yer alan değişken, diğer değişkenleri daha çok etkilemekte ve diğerlerinden az oranda etkilenmektedir. Dolayısıyla, VAR modeli kullanan ampirik çalışmalarda dışsal olan değişkenlere genellikle ilk sıralarda yer verilmektedir. Bu çalışmada değişkenler \{Endüstriyel üretim endeksi, tüketici fiyat endeksi, bankalararası gecelik basit faiz oranı\} şeklinde sıralanmıştır. 
Şekil 1. 1990: 01 - 2001: 12 Dönemi Etki - Tepki Fonksiyonları

a) Büyümenin faiz şokuna tepkisi

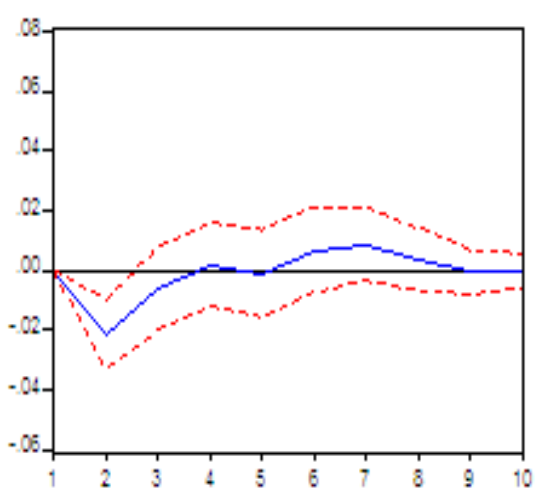

b) Enflasyonun faiz şokuna tepkisi

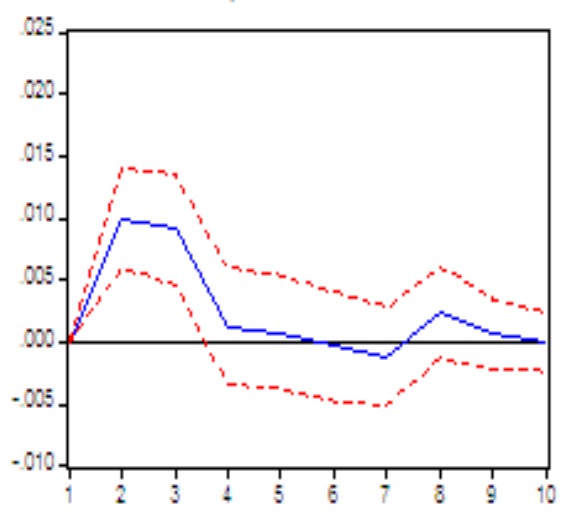

Şekil 1'de 1990: 01-2001: 12 döneminde faiz oranındaki şoka karş1l1k enflasyon ve endüstriyel büyüme oranının verdiği tepki görülmektedir. İlk grafiği incelediğimizde, para politikasındaki şoka karşılık (faizdeki artış), endüstriyel üretimin azaldığı, bu etkinin yaklaşık 4 ay sonra ortadan kalktığı görülmektedir. Diğer taraftan ikinci grafikten görüldüğü gibi, para politikasındaki şoka enflasyon artış ile tepki vermekte ve şokun etkisinin ortadan kalkması yaklaşık 6 ay almaktadır.

Faiz oranlarındaki şoklara enflasyonun artarak tepki vermesi, faiz oranlarındaki şokların üreticilerin borçlanma maliyetlerini arttırarak maliyet enflasyonuna sebep olmasından kaynaklanabilir. Diğer taraftan, Fisher Denklemi $i=r+\pi_{e}$ 'den hareketle nominal faizlerin, $i$, artması, enflasyon beklentilerinin, $\pi_{e}$, artması olarak yorumlanabilir. Fisher denklemine göre, nominal faiz ve beklenen enflasyon bire bir hareket etmekte ve reel faiz, $r$, durağan bir seyir izlemektedir $\left(r=i-\pi_{e}\right)$. Bu dönemde enflasyonun para politikası şokuna pozitif tepki vermesi, nominal faizlerin artmasının enflasyon beklentilerini artırarak sonuçta enflasyon artışına yol açması ile açıklanabilir. 
Şekil 2. 2002: 01 - 2005: 12 Dönemi Etki - Tepki Fonksiyonları

a) Büyümenin faiz şokuna tepkisi

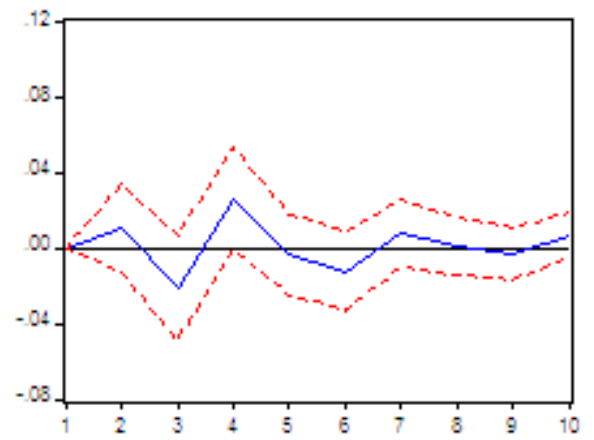

b) Enflasyonun faiz şokuna tepkisi

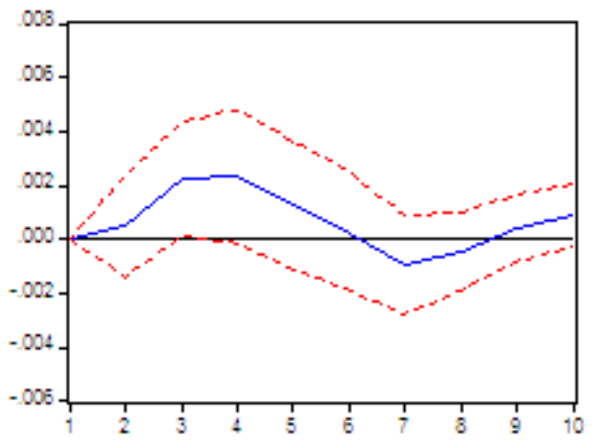

Şekil 2'de 2002:01 - 2005:12 örtük enflasyon hedeflemesi döneminde para politikasındaki şoka, endüstriyel üretimin (IP) ve enflasyon oranının (CPI) tepkisinin istatistiksel olarak anlamsız olduğu görülmektedir.

Şekil 3. 2006:01 - 2012:06 Dönemi Etki - Tepki Fonksiyonları

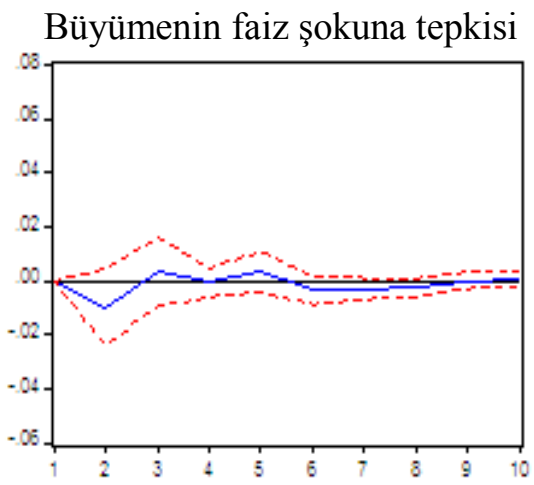

b) Enflasyonun faiz şokuna tepkisi

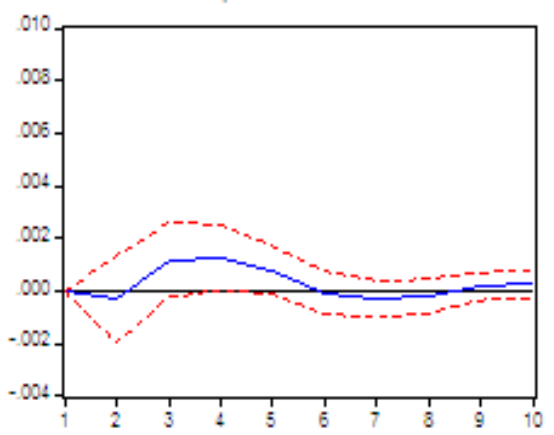

Şekil 3(b)'den görüldüğü gibi 2006: 01-2013: 08 açık enflasyon hedeflemesi döneminde faiz oranındaki şoka enflasyonun tepkisi önce düşüş sonra artış şeklinde olmaktadır. Ancak bu sonuç istatistiksel olarak anlamsızdır. Normal olarak faizin artmas1 enflasyon beklentilerinin artması şeklinde yorumlanmaktadır. Etki tepki fonksiyonuna göre, bu ilişkinin enflasyon hedeflemesi döneminde kırılmış olduğu görülmektedir. Bu durumun nedeni, enflasyon hedeflemesi stratejisine duyulan güvenin, piyasanın enflasyon 
beklentilerini hemen arttırma eğiliminde olmasını önlemesi olabilir. Endüstriyel büyüme oranının, para politikası şokuna verdiği tepki ise örtük enflasyon döneminde olduğu gibi istatistiksel olarak anlamsızdır. Dolayısıyla enflasyon hedeflemesi döneminde para politikasının büyüme üzerinde olumsuz bir etki yarattığına dair bir bulgu saptanmamıştır.

\section{SONUÇ}

1970'lerin ortalarından itibaren yüksek enflasyon Türkiye ekonomisinin başlıca sorununu teşkil etmiş ve enflasyonun yolaçtığı belirsizlik ortamı yatırımları da olumsuz etkileyerek büyüme potansiyelini aşağı çekmiş, diğer taraftan istikrarsız büyüme dinamiğine yolaçmıştır. Bu dönemde enflasyonu düşürmeye yönelik pek çok program uygulanmıştır. Bu çalışmada 2006 yılından itibaren uygulanan enflasyon hedeflemesinin Türkiye'deki performansını değerlendirmek amaçlanmıştır. Öncelikle hedeflenen enflasyon oranları ile gerçekleşen enflasyon oranları karşılaştırıldığında örtük enflasyon döneminde, gerçekleşen enflasyonun hedeflenenin altında olduğu görülmüştür. Açık enflasyon hedeflemesi döneminde ise 2009 ve 2010 yılları dışında gerçekleşen enflasyonun, hedeflenen enflasyonun üzerinde seyrettiği görülmektedir. $\mathrm{Bu}$ sonuçta, 2007 y1lında başlayan ve 2008 yılında derinleşen küresel krizin yol açtığ 1 belirsizlikler ve enerji fiyatlarındaki artışlar etkili olmuştur. TCMB'nin kontrolünde olmayan bu unsurlar, hedeflerin tutturulmasını zorlaştırmıştır. Enflasyon hedeflerinin tutturulamamasının tek başına enflasyon hedeflemesi rejiminin başarısız olduğunu göstermediği kabul edilmekte ve bu stratejinin ortalama enflasyon ve enflasyon sürekliliğine etkisi değerlendirilmektedir. Enflasyon ortalamasına bakıldığında hem örtük enflasyon hedeflemesi döneminde hem de açık enflasyon hedeflemesi döneminde ortalama enflasyonun azaldığı görülmüştür. Enflasyon sürekliliği ise yine hem örtük enflasyon hedeflemesi hem de açık enflasyon hedeflemesi dönemlerinde azalmıştır. Normal olarak enflasyon sürekliliğinin azalmasının enflasyon oynaklığının da azalmasına yolaçacağı beklenmektedir. Analiz sonucunda da beklendiği şekilde enflasyondaki değikenliğin göstergesi olan standart sapmanın azaldığı görülmüştür. Enflasyon hedeflemesi döneminde ortalama büyüme oranında bir miktar azalma olduğu görülmektedir. Gelişmekte olan ülkelerin global ekonomideki dalgalanmalara oldukça duyarlı olduğu dikkate alındığında büyüme oranındaki bu azalmanın global krizin yolaçtığı olumsuzluklardan da kaynaklanabileceği unutulmamalıdır. Çıktı oynaklığı ise enflasyon hedeflemesi döneminde, enflasyon hedeflemesi öncesi döneme oranla az bir miktar azalma göstermektedir.

Son olarak enflasyon hedeflemesi öncesi ve sonrası dönemde para politikası şoklarına enflasyonun ve endüstriyel büyümenin verdiği tepkiyi 
görmek için, etki-tepki fonksiyonları analiz edilmiştir. Enflasyon hedeflemesi öncesi (1990 :1-2001: 12) dönemde para politikası şokunun, enflasyon oranında artışa yol açtığı görülmüştür. Fisher denklemine göre, nominal faizlerdeki artış, enflasyon beklentilerini arttırarak enflasyonda artışa yol açabilmektedir. Diğer taraftan bu dönemde faizdeki artış endüstriyel büyümeyi azaltmaktadır. Bu ise, faizlerdeki artışın yatırım ve tüketim harcamalarını azaltarak büyümeyi olumsuz etkilemesiyle açıklanabilir. Örtük enflasyon ve açık enflasyon hedeflemesi dönemlerinde ise, para politikasındaki şoka enflasyon oranının ve endüstriyel büyümenin verdiği tepkinin istatistiksel olarak anlamsız olduğu görülmüştür. Para politikası şokunun enflasyonda artışa yolaçan etkisinin enflasyon hedeflemesi döneminde ortadan kalkması, enflasyon hedeflemesi rejimine duyulan güven arttıkça, enflasyon beklentileri oluşturulurken hedeflenen enflasyon oranlarının dikkate alındığına işaret edebilir. Ayrıca analizler, enflasyon hedeflemesinin çıtı büyümesi üzerinde olumsuz bir etki yarattığına dair bir bulgu ortaya koymamaktadır. Dolayısıyla, çalışmanın sonuçları enflasyon hedeflemesinin çıktı büyümesi üzerinde açık bir maliyet yaratmadan, enflasyonun düşürülmesi için uygun bir ortam yarattığını göstermektedir.

\section{NOTLAR}

${ }^{1}$ Örtük enflasyon hedeflemesi stratejisinde de bir enflasyon hedefi belirlenmektedir ve para politikaları gelecek dönem enflasyona odaklanarak yürütülmektedir. Kısa vadeli faiz oranları yine temel para politikası aracıdır. Örtük enflasyon hedefi yaklaşımında da faiz oranında yapılan değişikliklerin gerekçeleri kamuoyu ile paylaşılmaktadır. Ancak enflasyon hedeflemesi yaklaşımından farklı olarak, para politikası kurulunun toplantı tarihleri kamuoyu tarafindan bilinmemekte ve para politikası kurulunda faiz kararı ile ilgili oylama olmamaktadır (Ersel, Özatay, 2008).

2 T.C. Merkez Bankası enflasyon hedeflerini TÜFE (CPI) üzerine koymaktadır. Bu endeks kamuoyu tarafindan yakından takip edilmekte ve ekonomik birimler kararlarını verirken bu endeksi dikkate almaktadır. Enflasyon hedeflemesinin performansını analiz eden çalışmalarda genelde enflasyon değişkeni olarak TÜFE kullanılmaktadır. Bu çalışmalarla uyum sağlamak ve karşılaştırma yapabilmek açısından burada da TÜFE değişkeni kullanılmıştır.

\section{KAYNAKÇA}

Akyazı, H., A. Ekinci (2008) "Enflasyon Hedeflemesi Rejiminin Performans1: Gelişmekte Olan Ülkeler ve Türkiye Karşılaştırması”, Marmara Üniversitei İ.I.B.F. Dergisi, XXIV, 1.

Aşıkoğlu, Y., M. Uçtum (1992) “A Critical Evaluation of Exchange Rate Policy in Turkey”, World Development, 20(10), 1501-1514. 
Ball, L.P. (1992) "Why Does High Inflation Raise Inflation Uncertainty?” Journal of Monetary Economics, 29(3), 371-388.

Ball, L., N. Sheridan (2003) “Does Inflation Targeting Matter?” NBER Calışma Tebliği, No. 9577.

Bernanke, B. S., S. F. Mishkin (1997) "Inflation Targeting: A New Framework for Monetary Policy?” NBER Working Paper Series, No. 5893.

Bernanke, B., T. Laubach, F. Mishkin, A. Posen (1999) Inflation Targeting: Lessons from the International Experience, Princeton: Princeton University Press.

Bryan, M.F., S.G. Cecchetti, R.L. Wiggins (1997) "Efficient Inflation Estimation" NBER Working Paper, No. 6183.

Cecchetti, G., M. Ehrmann (1999) "Does Inflation Targeting Increase Output Volatility? An International Comparison of Policymakers' Preferences and Outcomes" NBER Working Paper, No. 7426.

Corbo, V., O. Landarretche, K. Schmidt-Hebbel (2002) "Does Inflation Targeting Make a Difference, in Inflation Targeting : Design, Performance, Challenges", in N. Loayza, R. Soto (ed.), Inflation Targeting: Design, Performance, Challenges, Santiago: Central Bank of Chile, 221-69.

Cukierman, A., A. Meltzer (1986) “A Theory of Ambiguity, Credibiliry and Inflation Under Discretion and Asymmetric Inflation”, Econometrica, 54(5), 1099 1128.

Ersel, H., F. Özatay (2008) "Fiscal Dominance and Inflation Targeting: Lessons from Turkey”, Emerging Markets Finance \& Trade, November-December Issue, 44(6), 38-51.

Ermişoğlu, E. (2013) “Türkiye'de Enflasyon Hedeflemesi: Bir Başarı Hikayesi mi?”, BDDK Bankacılık ve Finansal Piyasalar, 7(1), 31-58.

Folkertsma, C.K., K. Hubrich (2001) "Performance of Core Inflation Measures", Economist, 149(4), 455-508.

Friedman, M. (1997) "Nobel Lecture: Inflation and Unemployment", Journal of Political Economy, 85(3), 451-472.

Friedman, B., K.N. Kuttner (1996) “A Price Target for U.S. Monetary Policy? Lessons from the Experience with Money Growth Targets", Brooking Papers on Economic Activity, 1, 77-125.

Genç, İ.H., M. Balcılar (2012) "Effectiveness of Inflation Targeting in Turkey", Emerging Markets Finance and Trade, 48(5), 35-47. 
Johnson, D.R. (2002) "The Effect of Inflation Targeting on the Behavior of Expected Inflation: Evidence from an 11 Country Panel", Journal of Monetary Economics, 49(8), 1521-1538.

Jonas, J., F.S. Mishkin (2003) "Inflation Targeting in Transition Countries: Experience and Prospects", NBER Working Paper Series, No. 9667.

Kahn, G., K. Parrish (1998) "Conducting Monetary Policy with Inflation Targets," Federal Reserve Bank of Kansas City Economic Review, 83, 5-32.

Kara, H., F. Öğünç (2008) "Inflation Targeting and Exchange Rate Pass-Through: The Turkish Experience”, Emerging Markets Finance\&Trade, NovemberDecember, 44(6), 52-66.

Kim, S., Y.C. Park (2006) "Inflation Targeting in Korea: a Model of Success?”, BIS Paper, No. 31, 140-164.

King, M. (2002) The inflation Target Ten Years On, Speech Delivered to the London School of Economics, 19 November 2002, London.

Levin, A.T., F.M. Natalucci, J.M. Piger (2004) "The Macroeconomic Effects of Inflation Targeting”, Federal Reserve Bank of St Louis Review, 86(4), 5180.

Lin, S., H. Ye (2009) "Does Inflation Targeting Make a Difference in Developing Countries?", Journal of Development Economics, 89(1),118-123.

Mendonça, H.F. (2007) "Empirical Evidence from Fourteen Countries with Explicit Inflation Targeting”, Applied Economics Letters, 14(8), 573-576.

Mishkin, F.S. (1999) "International Experiences with Different Monetary Policy Regimes", Journal of Monetary Economics, 43(3), 579-605.

Mishkin, F.S. (2000) "Inflation Targeting in Emerging Market Countries", NBER Working Paper Series, No. 7618.

Mishkin, F.S., A.S. Posen (1997) "Inflation Targeting: Lessons from Four Countries". Federal Reserve Bank of New York, Economic Policy Review, 3(3), 9-110,

Mishkin, F.S., K. Schmidt-Hebbel (2001) "One Decade of Inflation Targeting in the World: What Do We Know and What Do We Need to Know?" NBER Working Paper Series, no. 8397.

Mishkin, F.S., K. Schmidt-Hebbel (2007) "Does InflationTargeting Make a Difference", Working Paper Series, No.12876.

Neumann, M. J. M., J. von Hagen (2002) “Does Inflation Targeting Matter?”, Center for European Integration Studies, ZEI Working Paper, No. B 01-2002. 
Neyapt1, B. (2012) "Monetary Institutions and Inflation Performance", Journal of Economic Policy Reform, 15(4), 339-354.

Özatay, F. (2011) Parasal İktisat Kuram ve Politika, Ankara: Efil Yayınevi.

Petursson, T.G. (2004) "The Effects of Inflation Targeting on Macroeconomic Performance”, Central Bank of Iceland Working Papers, No. 23.

Petursson, T.G. (2005) "Inflation Targeting and Its Effects on Macroeconomic Performance", SUERF Studies, SUERF-The European Money and Finance Forum, Number 2005/5 M. Balling, (ed.).

Roger, S. (1997) “A Robust Measure of Core Inflation in New Zealand, 1949-1996", Reserve Bank of New Zealand Discussion Paper Series, No. G97/7.

Schaechter, A., M.R. Stone, M. Zelner (2000) “Adopting Inflation Targeting: Practical Issues for Emerging Countries”, Occasional Paper, No. 202, New York: (IMF).

Siklos, P.L. (1999) "Inflation-Target Design: Changing Inflation Performance and Persistence in Industrial Countries", Federal Reserve Bank of St. Louis Review, March/April, 47-58.

Svensson, L.E.O. (1997) "Inflation Forecast Targeting: Implementing and Monitoring Inflation Targets”, European Economic Review, 41(6),1111-46.

Svensson, L.E.O. (1999) "Inflation Targeting as a Monetary Policy Rule”, Journal of Monetary Economics, 43(3), 607-654.

Svensson, L.E.O. (2001) Independent Review of the Operation of Monetary Policy in New Zealand: A Report to the Minister of Finance, Stockholm: Institute for International Economic Studies, Stockholm University.

Svensson, L.E.O. (2010) "Inflation Targeting", NBER Working Paper Series, No. 16654.

Tagushi H., C. Kato (2010) "Assessing the Performance of Inflation Targeting in East Asian Economies”, Asian-Pasific Economic Literature, 93-102.

Türkiye Cumhuriyet Merkez Bankası (2009) 2009 Yılı Enflasyon Raporu -IV, Ankara. http://www.tcmb.gov.tr/

Türkiye Cumhuriyet Merkez Bankası (2010) 2010 Yılı Enflasyon Raporu -IV, Ankara. http://www.tcmb.gov.tr/

Türkiye Cumhuriyet Merkez Bankası (2012) 2012 Yılı Enflasyon Raporu -IV, Ankara. http://www.tcmb.gov.tr/ 
Enflasyon Hedeflemesi ve Türkiye Deneyimi 